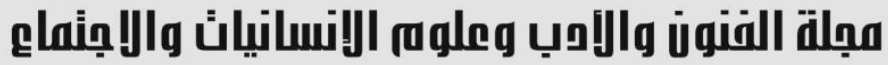

Journal of Arts, Literature, Humanities and Social Sciences www.jalhss.com

\section{الجمعيات التعاونية الفلاحية وأثرها في العملية الانتاجية في قضاء الزبير في العراق}

\section{م.م. محمسد حبيب العكيلي

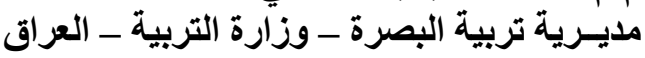 الايميل: Sadmohmed660@gmail.com}

المغض

تشكل الجمعيات التعاونية الفلاحية واحدة من أهم حلقات العملية الانتاجية الزراعية في جميع دول العالم أذ تعمل كأداة ووسيلة لتسهيل الكثير من المشكلات التي تعثرض طريق العملية الانتاجية الخاصة بالقطاع الزراعي ومن لن خلالها يمكن أيضا تتظيم وترتيب المجتمع الريفي ودعم الفلاح وتحسين وضعه الاجتماعي . تمحور البحث حول دور هذه الجمعيات في قضاء الزبير أحد اهم الاقضية الزراعية في محافظة البصرة والعر اق بصورة عامة مستهدفا توضيح دور هذه الجمعيات والاهداف التي قامت من أجلها واهم المشكلات التي تقف

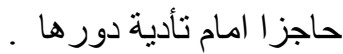
خلص البحث الى جملة من النتائج اهمها أن هذه الجمعيات تعاني من مشكلات عديدة في مقدمتها ضعف الدعم المادي و المعنوي المقدم من الجهات ذات العلاقة مع قلة و انعدام الوعي الثقافي بين السكان الريف حول اهمية هذه الجمعيات وقلة الكو ادر المتخصصة في هذا المجال فضلا عن مشكلات اخرى يعرضها البحث بالتفصيل . كما خرج البحث بمجموعة من التوصيات من شانها العمل على تدعيم الدور الريادي لهذه الجمعيات اذا ما تم العمل على تطبيقها ومنها تقديم الدعم بمختلف أنو اعه ليكون حافزا لزيادة عملها وتتجيع من يعمل بها مع تفعيل دور المصارف الزراعية التعاونية لتسهل من عمل هذه الجمعيات وكذلك العمل على توعية الاشخاص الذين

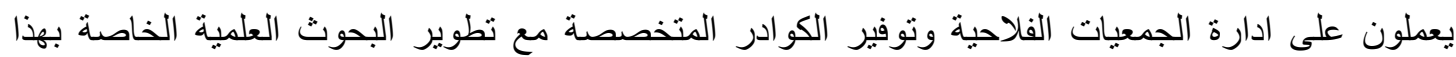
المجال ـ وان تكوت وزراه الزراعة وكافة المؤسسات التابعة لها الداعم الاساس لهذه العملية من خلال عمل الحملات الارشادية والتوعوية لتوضيح العمل التعاوني و أقامه الندو ات و المؤتمرات الخاصة بهذا المجال. 


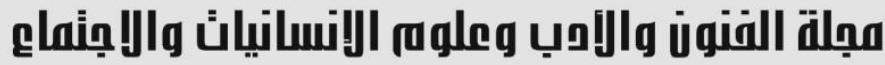 \\ Journal of Arts, Literature, Humanities and Social Sciences \\ www.jalhss.com \\ Volume (52) May 2020 \\ العدد (52) مايو 2020
}

\section{Agricultural Cooperative Societies and Their Impact on the Production Process in the Zubair District of Iraq}

\author{
Assist.Lect. Muhammad Habib Al-Aqili \\ Basra Education Directorate - Ministry of Education - Iraq \\ Email: sadmohmed660@gmail.com
}

\begin{abstract}
The agricultural cooperative societies constitute one of the most important links of the agricultural production process in all countries of the world, as it works as a tool and a means to facilitate many problems that hinder the process of the productive process for the agricultural sector, and through it, it is also possible to organize and arrange the rural community, support the farmer and improve his social status.

The research focused on the role of these societies in the Zubair district, one of the most important agricultural districts in Basra Governorate and Iraq in general, aiming to clarify the role of these associations and the goals for which they were established and the most important problems that stand in the way of fulfilling their role.

The research concluded a number of results, the most important of which is that these societies suffer from many problems, foremost of which is the weak material and moral support provided by the relevant authorities with the lack and lack of cultural awareness among the rural population about the importance of these associations and the lack of specialized cadres in this field as well as other problems presented in detail.

He also came out with a set of recommendations that would work to support the leadership role of these societies if they were applied and include support of various kinds to be an incentive to increase their work and encourage those working with them while activating the role of cooperative agricultural banks to facilitate the work of these associations as well as work to educate people who They work to manage agricultural societies and provide specialized cadres with the development of scientific research in this field and that the Ministry of Agriculture and all its affiliated institutions support the basis for this process through the work of extension and awareness campaigns to clarify the cooperative work and held seminars and For conferences in this field.
\end{abstract}

Keywords: agricultural societies, productive process, Al-Zubair district. 


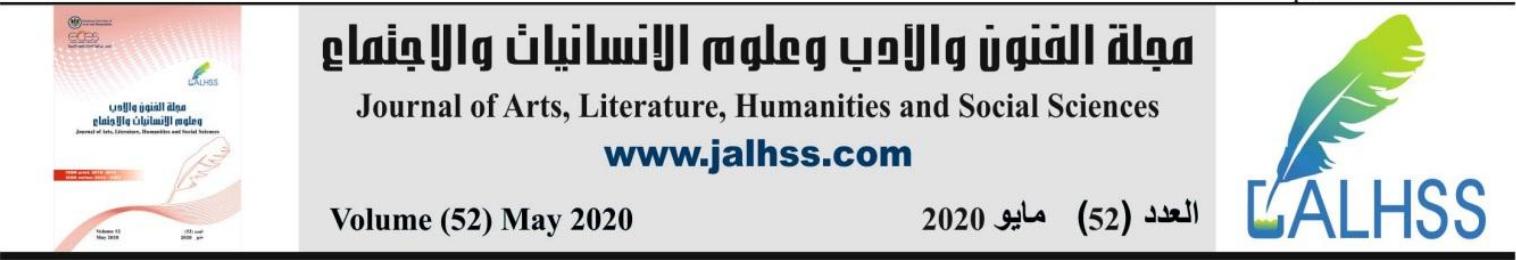

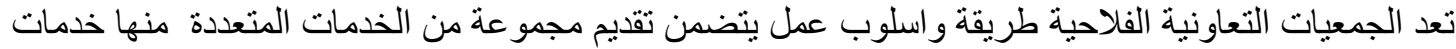

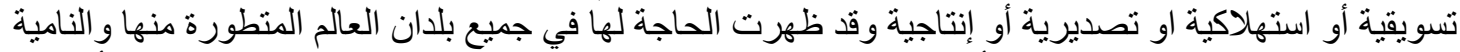

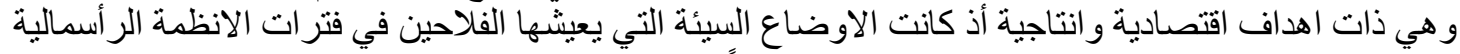

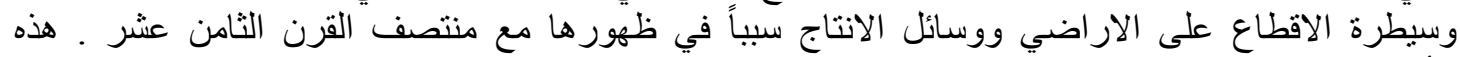

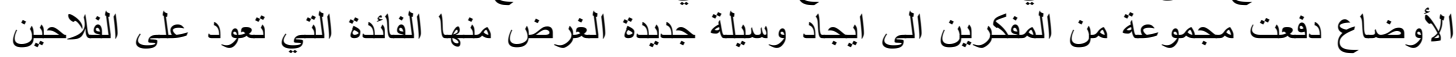

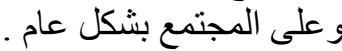

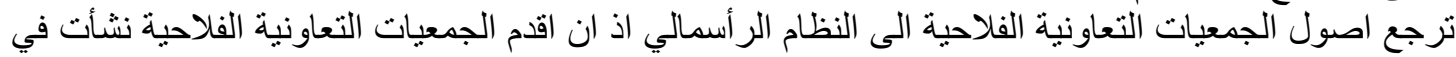

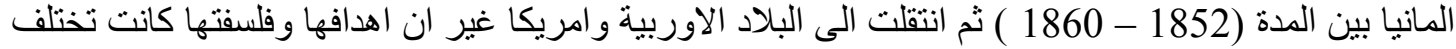

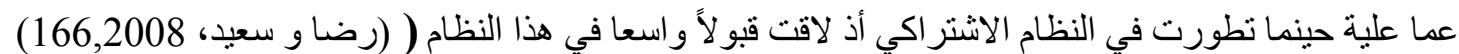

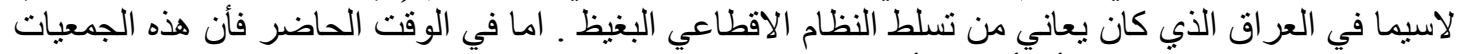

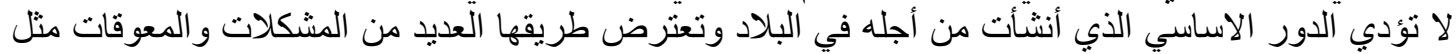

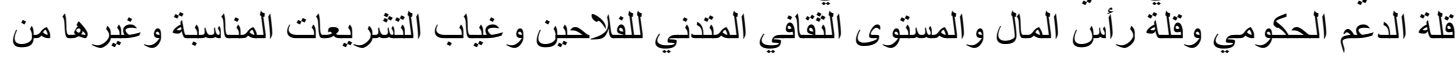

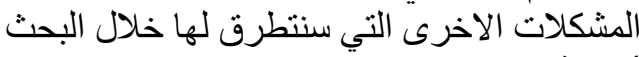

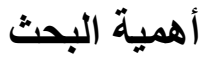

تتطلق اهمية البحث من الدور المهم الذي من الممكن ان تلعبه الجمعيات التعاونية الفلاحية في العملية الانتاجية

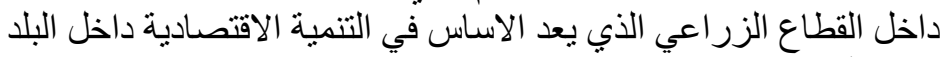

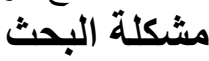

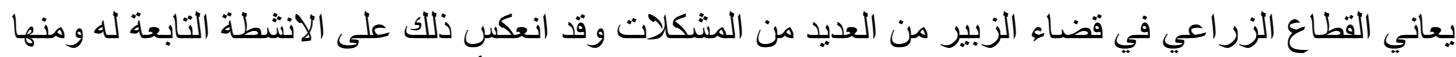

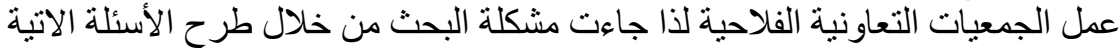

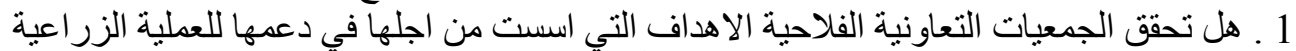

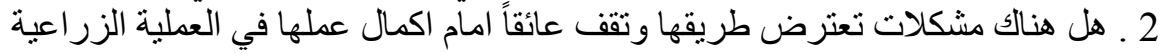
هدف البحث

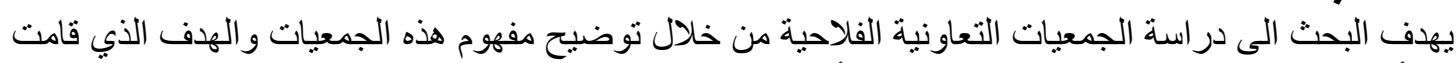

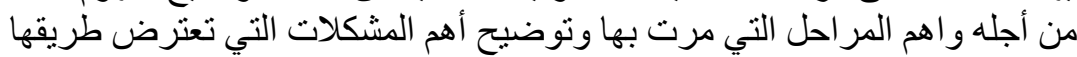

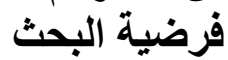
تتطلق فرضية البحث من منطلق أن الجمعيات التعاونية الفلاحية يمكن ان تؤدي دوراً مهماً في العملية الانتاجية

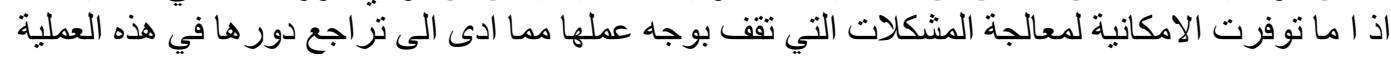

اقتضت الضرورة البحث يقسم البحث على عدة محاور تناول المحور الاول الى مفهوم الجمعيات التعاونية الفلاحية

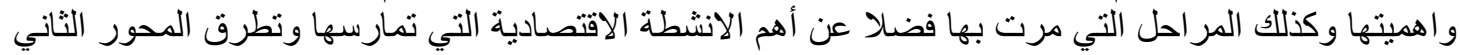

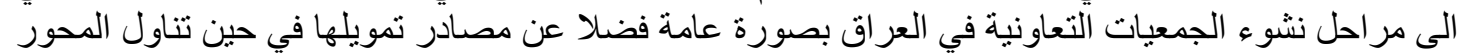

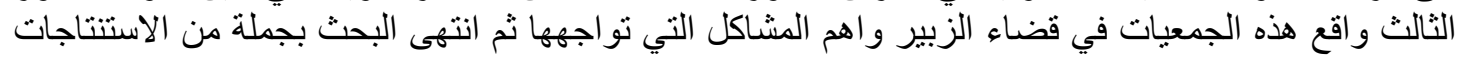

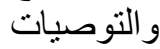
منطقة الار اسة ماتة

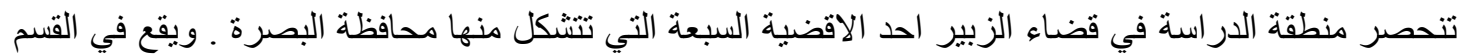

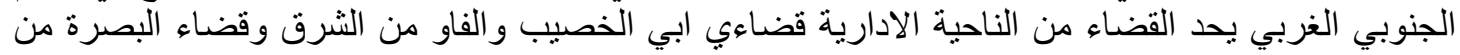

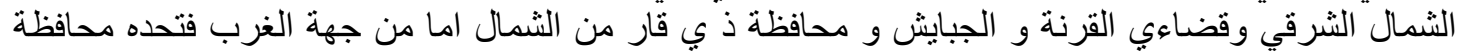

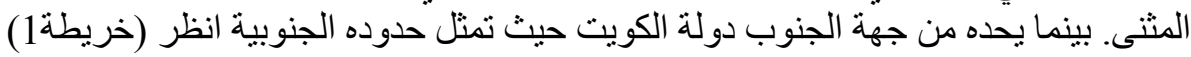




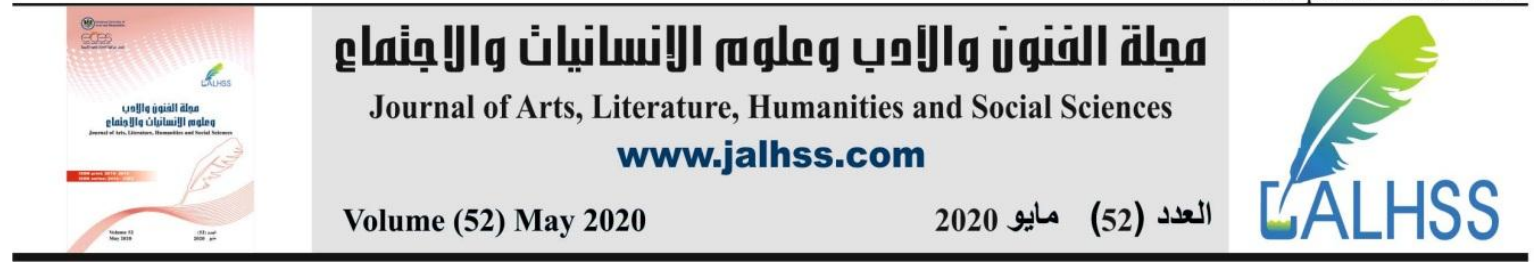

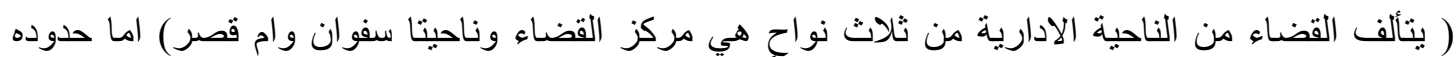

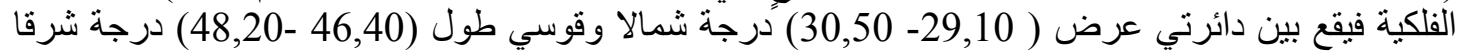

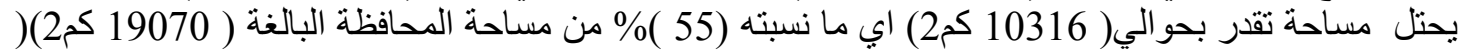
وزارة التخطيط، المجموعة الاحصائية ،2016) تبلغ مساحة مركز القضاء (27) (1134كم2) اي ما بعادل (11\%)

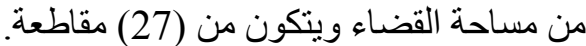

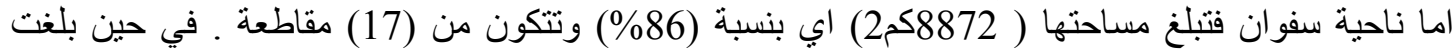

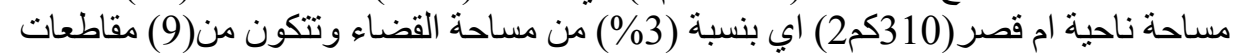




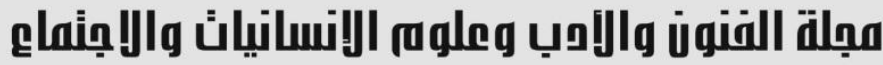

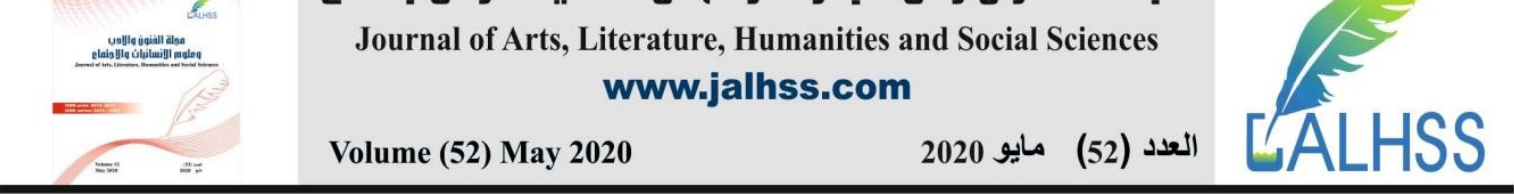

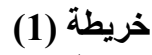

الموقع الجغرافي لقضاء الزبير من محافظة البصرة

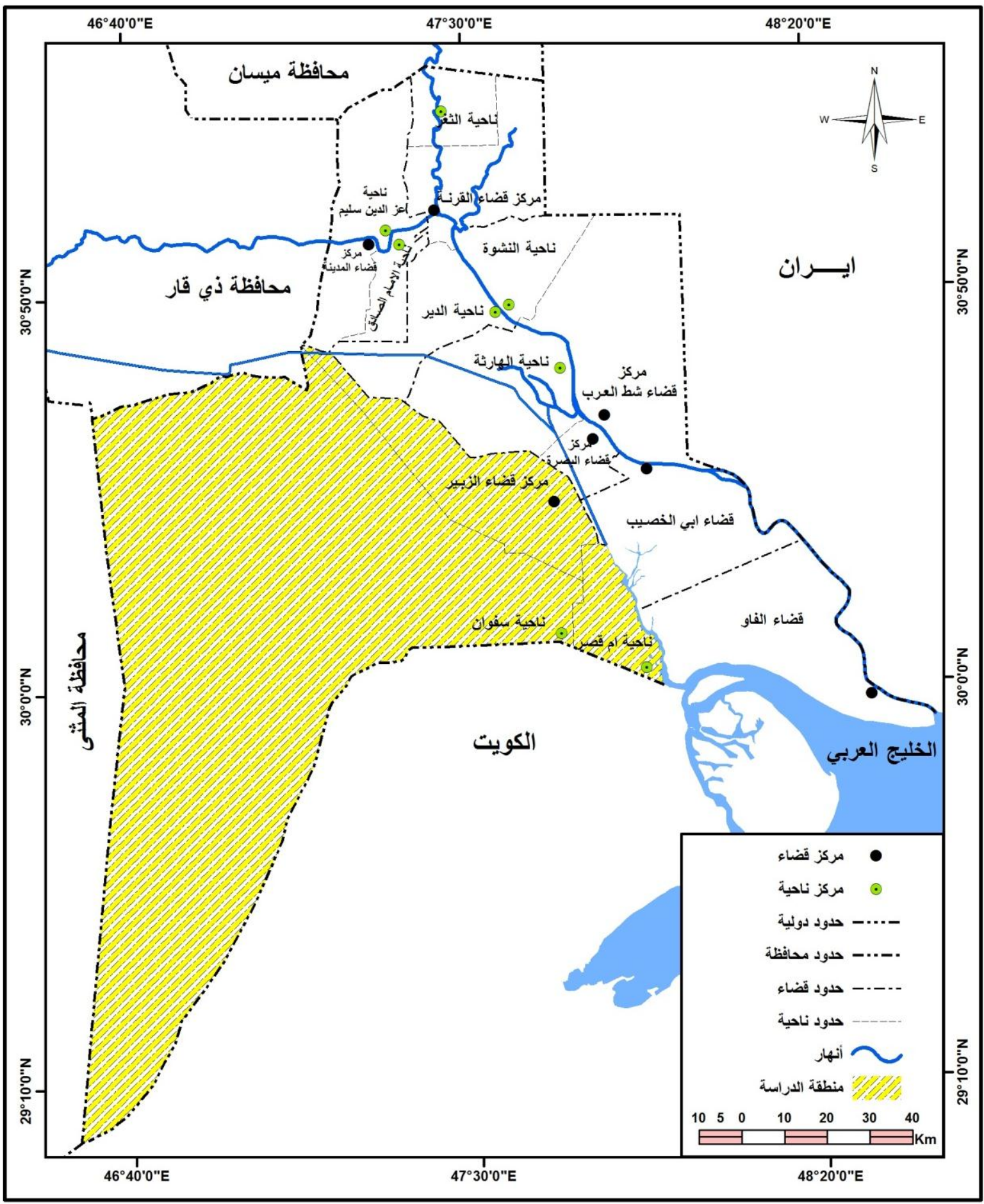

المصدر/ الهيئة العامة للمساحة، خريطة محافظة البصرة الادارية، مقياس الرسم 1/ 500000، سنة 2014 


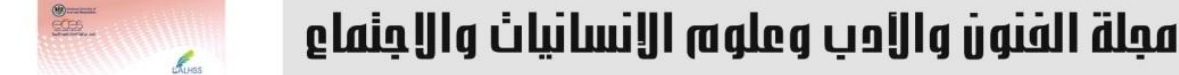 \\ Journal of Arts, Literature, Humanities and Social Sciences www.jalhss.com \\ مفهوم الجمعيات التعاونية الفلاحية واهميتها}

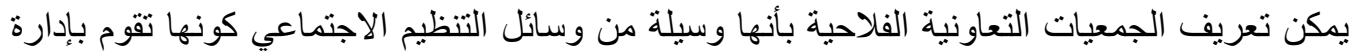

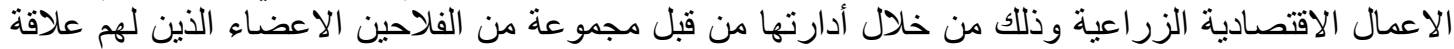

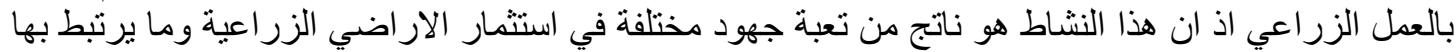

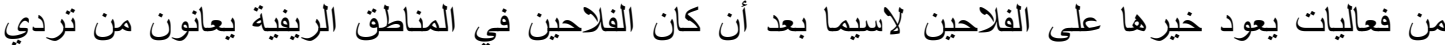

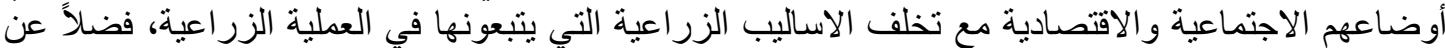

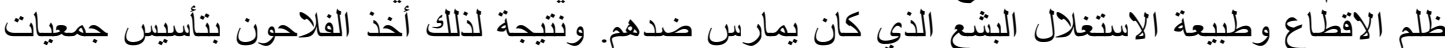

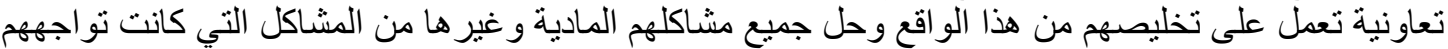

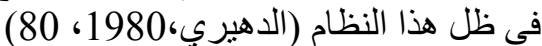

هذا وقد تعددت و المفاهيم و التعاريف التي عرفت الجمعيات التعاونية الفلاحية اذ عرفها العض على التي انها

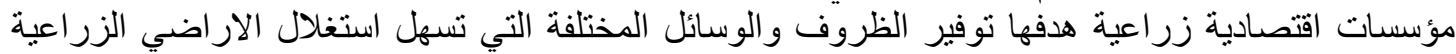

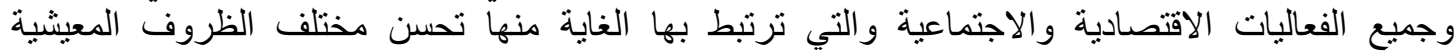

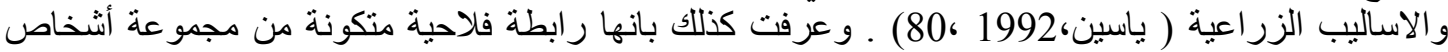

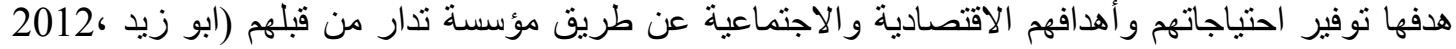

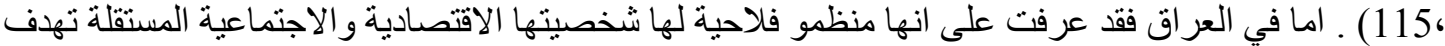

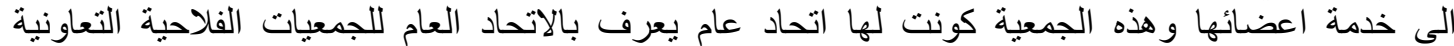

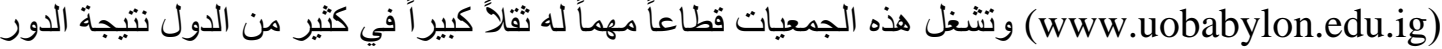

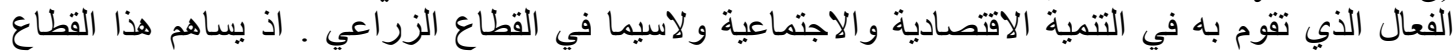

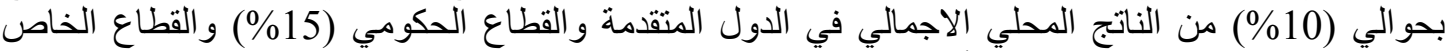

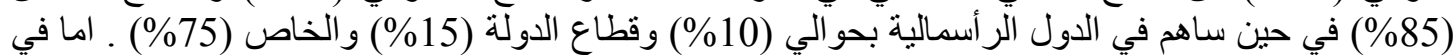

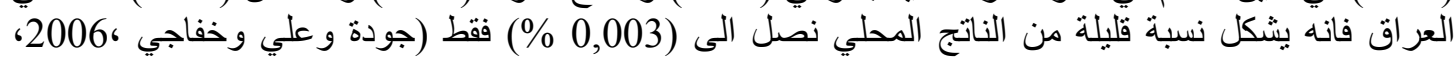

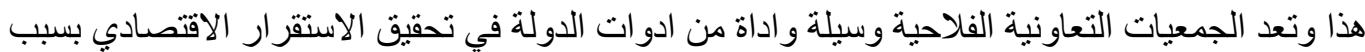

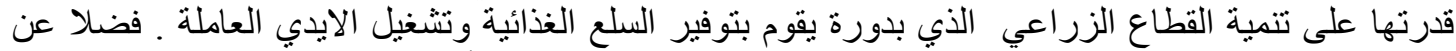

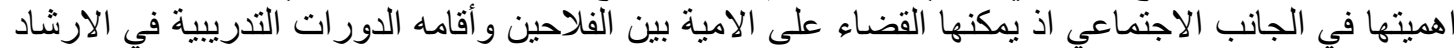

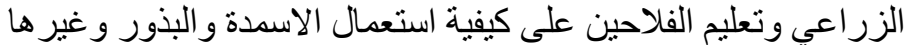

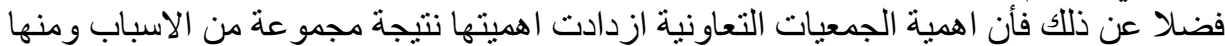

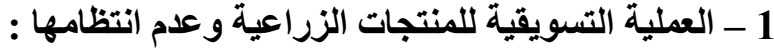
يتأثر الانتاج الزراعي بكثير من العو امل الطبيعية مما يؤدي الى على عدم انتظام تسويقه مما يتسبب بضعف مركز

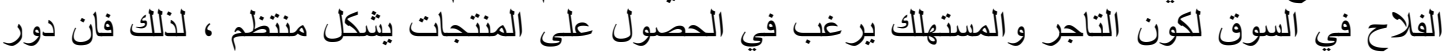
الجمعيات يعمل على تنظيم تسويق المنتجات بالثكل الذي يتيح للفلاح الحصول على الني الاسعار المناسبة

2 - تعمل الجمعيات التعاونية على القضاء على احتكار التجار والمرابين :

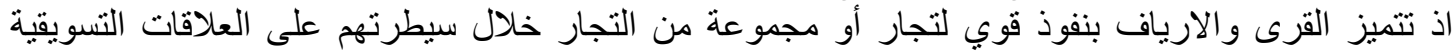

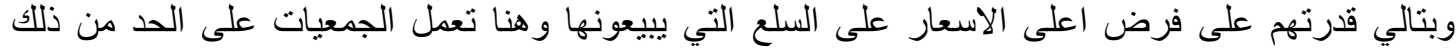

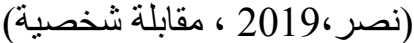
3 - تلف بعض المنتجات بسر عة كبيرة وهو حافز يشجع الفلاحين على تأسيس جمعيات فلاحية تنظم عملية التسويق 


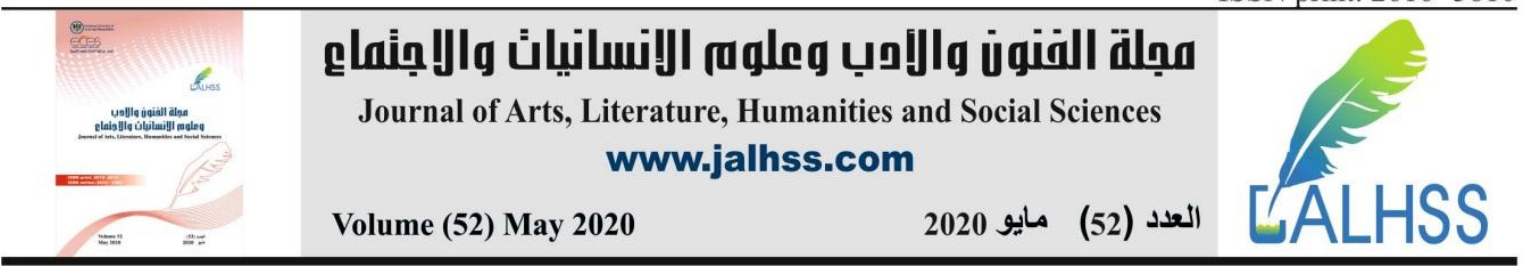

\section{المراحل التي مرت بها الجمعيات التعاونية الفلاحية}

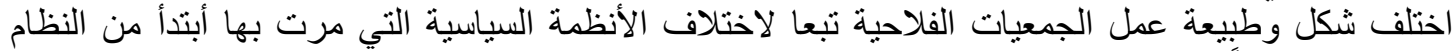
الر أسمالي مروراً بالنظام الاشتر اكي اذ تميزت الجمعيات بصفات خاصة ومعينة مع كل مرحلة من هذه المر احل الطل وكالاتي

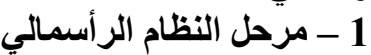
يعد التعاون ظاهرة اجتماعية ينضوي تحته العديد من الانشطة الجماعية بين الأفر اد تتثنل بالتضامن و المساعدة

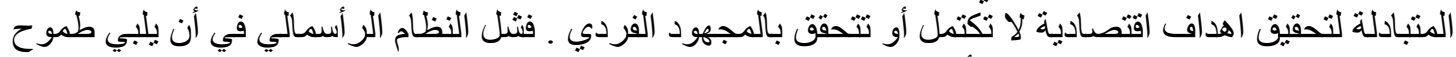

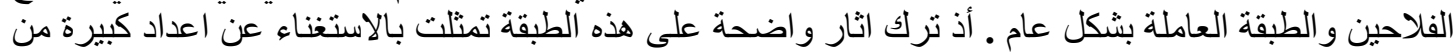

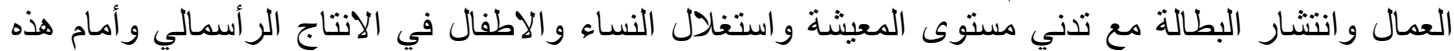

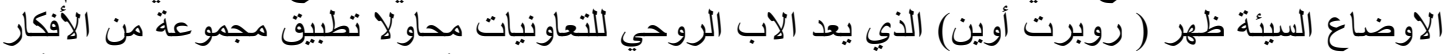

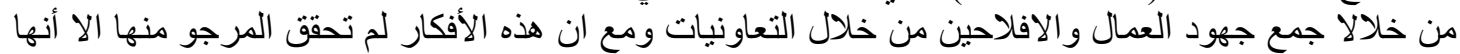
كانت نقطة انطلاق لتعاونيات العالمية (عانور ،

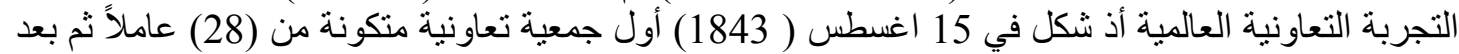

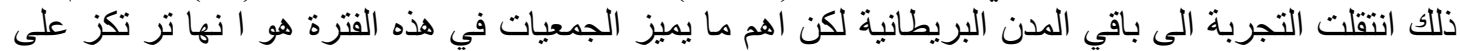

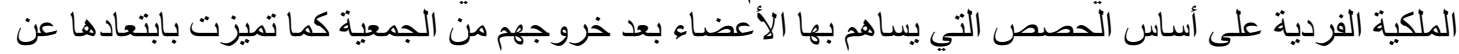

هدفها الاسمى و هو تنمية القطاع الزر اعي ورفع المستوى المعيشي للفلاح ( العتيبي، www.grenc.com)

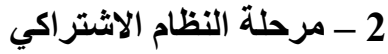

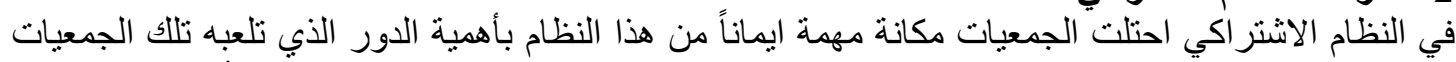

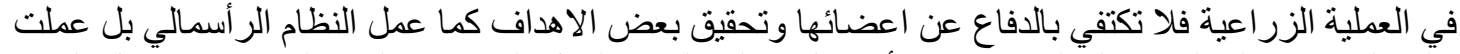

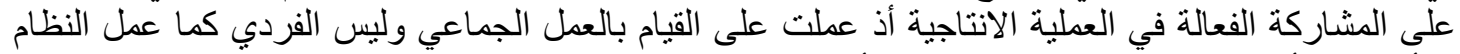

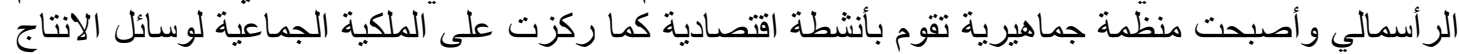

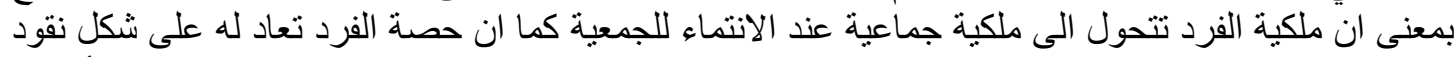
عند الخروج من الجمعية وفيما يخص عائد هذه الجمعيات فيوزع حسب علئ عمل العضو وليس حسب رلئ رأسماله

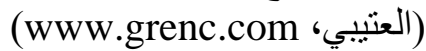
لكن اهم ما تميزت به الجمعيات في ظزل هذا النظام هو أ ـ تكليفها بمهام عديدة تشاهم في تعزيز علاقات الاتنتاج الاشتراكي والعمل على حل المشكلات التي تواجه

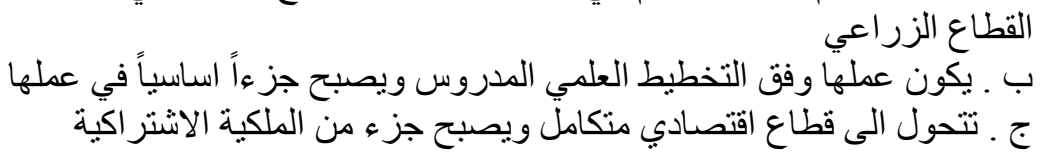

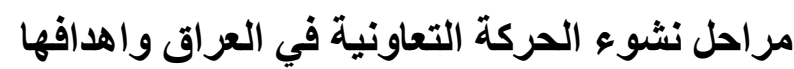

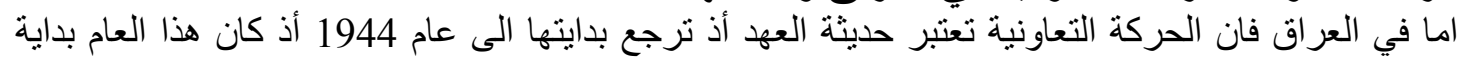

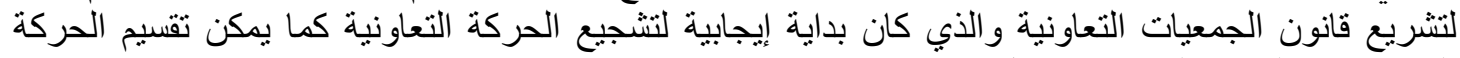
التعاونية في العراق الى عدة مر احل كالآتي

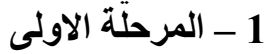
كانت بدايتها مع صدور قانون التعاون رقم (27) لسنة 1944 أذ شملت أحكام هذا القانون جميع انواع واع واثكال التعاون الزر اعي أذ تنكل منذ أصدار هذا القانون ولغاية 1958 (157) جمعية (الجبوري، لني، 1989، 15)

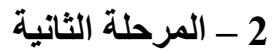

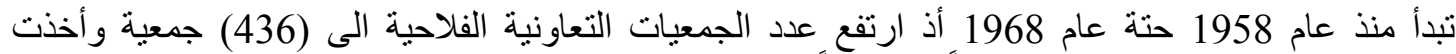

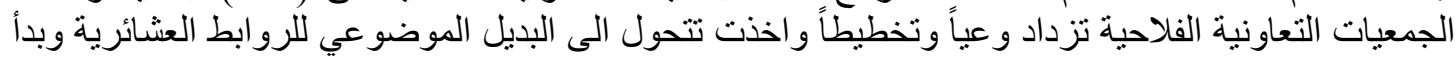

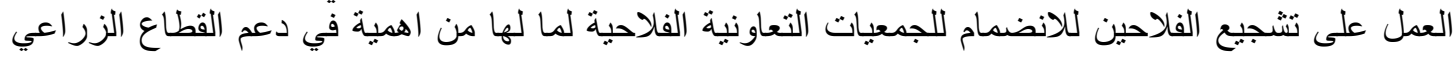




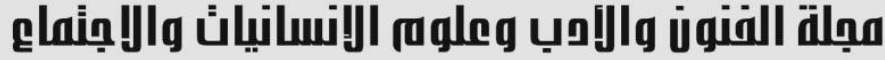

Journal of Arts, Literature, Humanities and Social Sciences www.jalhss.com

وتتمية الاتتاج ـ كما تميزت هذه الفترة بتجمع الملكيات الصفيرة والحيازات وضمها ضمن المنات أثكال التعاونية

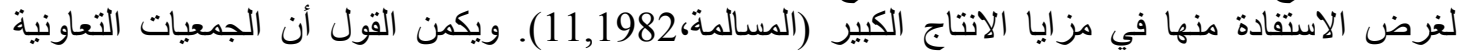

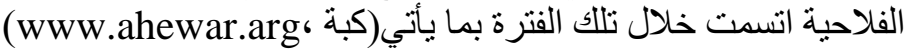

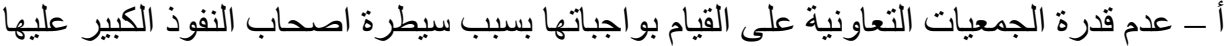
ب - نتيجة قلة الوعي الثقافي والإداري لدة معظم الثيام الفلاحين وعدم معرفتهم بأهم المزايا التي تتميز بها هذها

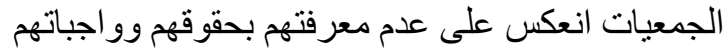
ج - قلة الكادر الفني و الاداري المدرب الذي يقوم بتوجيه هذه الجمعيات و الاشر اف على عملها

3 - تبر ملة الثالثة

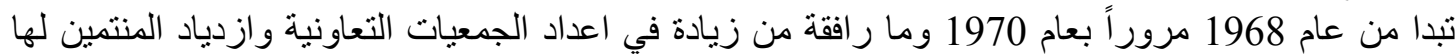

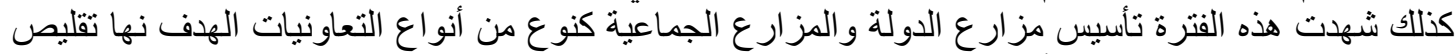

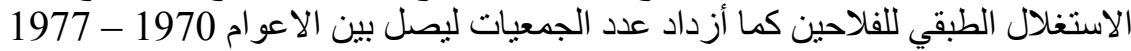

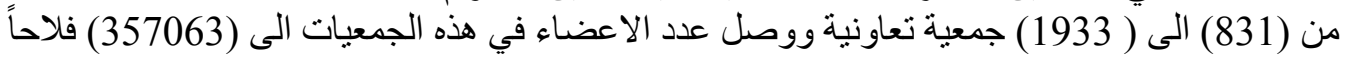

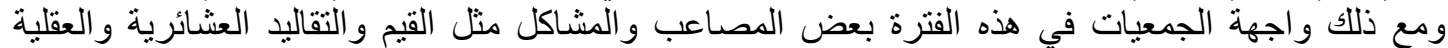

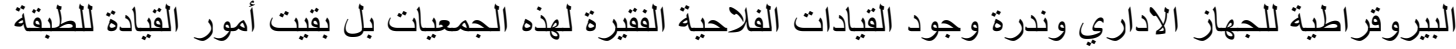

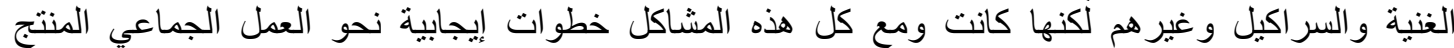

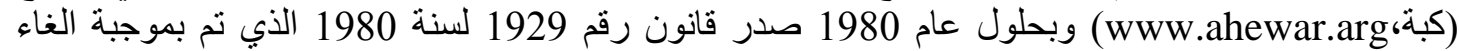

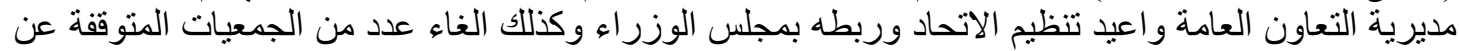

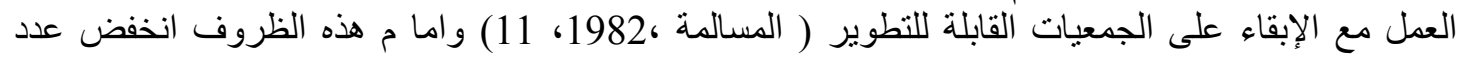

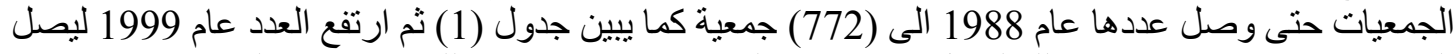

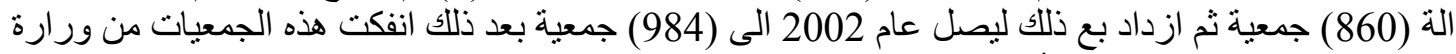

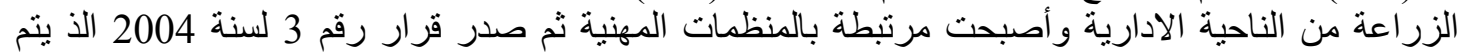

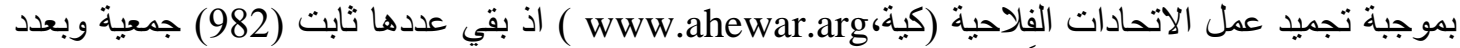

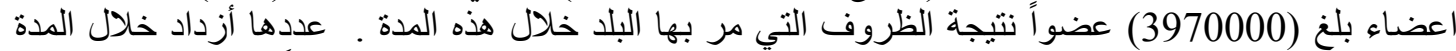

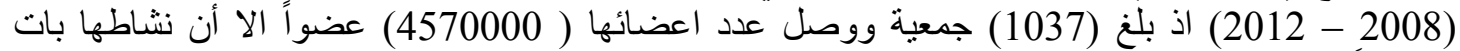

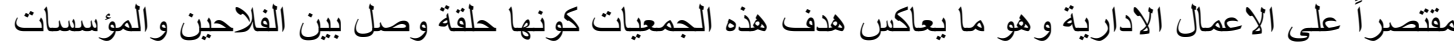

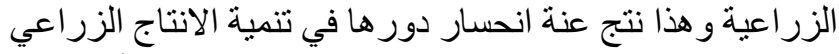

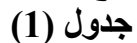

الجمعيات التعاونية الفلاحية و عدد اعضائها في العراق للمدة (1980 - 2012)

\begin{tabular}{|c|c|c|}
\hline ع عدد الاعضاء & عداء الجمعيات & السنو \\
\hline 378831 & 2014 & 1980 \\
\hline 360498 & 772 & 1988 \\
\hline 224271 & 799 & 1998 \\
\hline 230103 & 860 & 1999 \\
\hline 238906 & 922 & 2000 \\
\hline 221603 & 933 & 2001 \\
\hline 4170000 & 984 & 2002 \\
\hline 3970000 & 982 & 2003 \\
\hline 3970000 & 982 & 2007 \\
\hline 4570000 & 1037 & 2008 \\
\hline 4570000 & 1037 & 2012 \\
\hline
\end{tabular}

المصدر : تم اعداد الجدول بالاعتماد على الجى الجماع.

وزارة التخطيط ، الجهاز المركزي للإحصاء، المجموعة الاحصائية السنوية للأعوام (1980 -2012) 


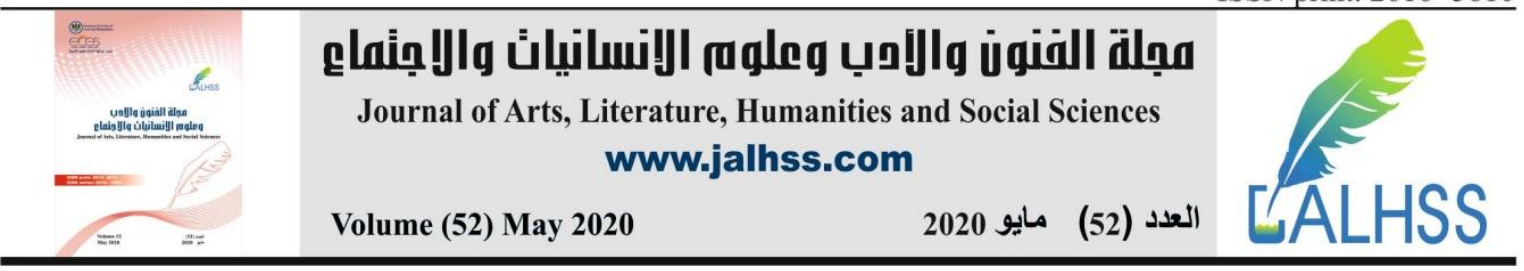

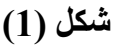

الجمعيات التعاونية الفلاحية في العراق للمدة (1980 -2012 )

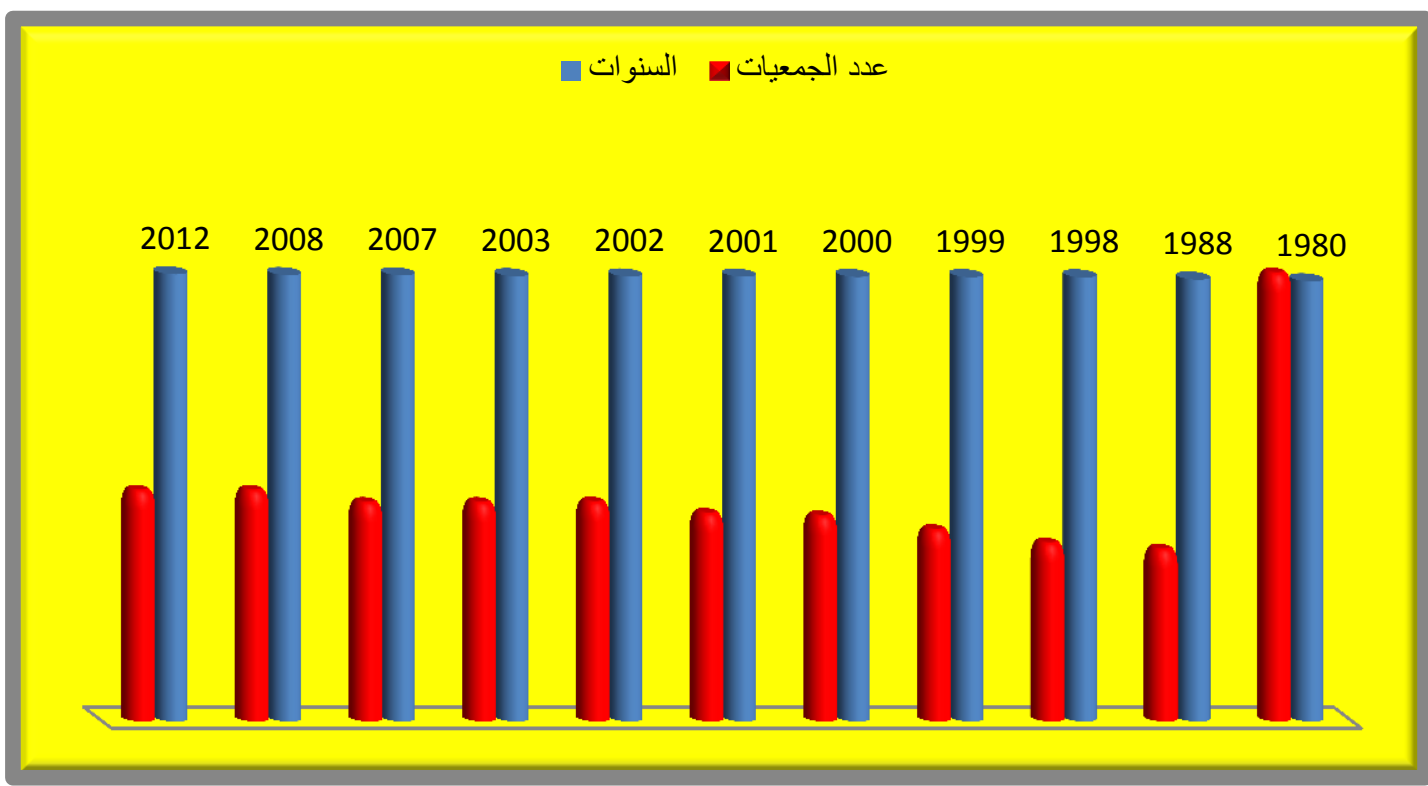

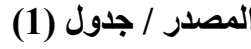

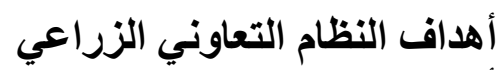
أن من اهم الاهداف التي يسعى النظام التعاوني الزراعي التئي الى تحقيقها هي العمل على رفع مستوى الحياه المعاثنية

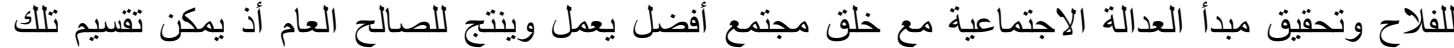

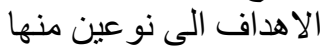
1 - 2 - 2 أهداف اقتصادية

تسعى الجمعيات التعاونية لتحقيق التضامن بدلاً من التنافس في الحياة الاقتصادية بمنع استغلال الإنسان الإنسان لأخية

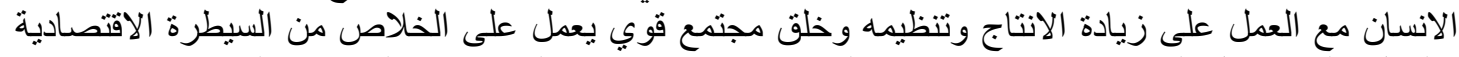

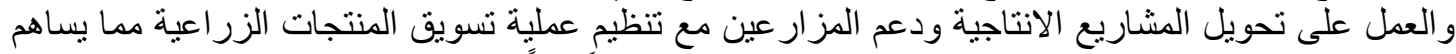

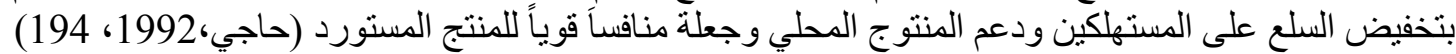

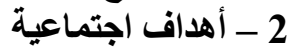
تتمل هذه الاهداف على خلق روح التضامن والتضحية ومحاربة الطائفية مع تعزيز ونشر الوعي التعاوني من التوني

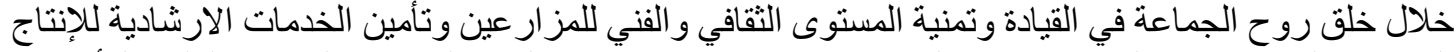

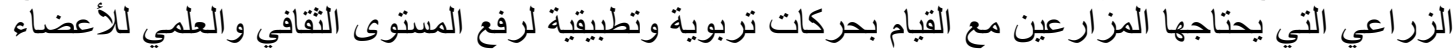

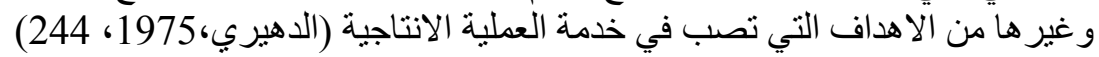




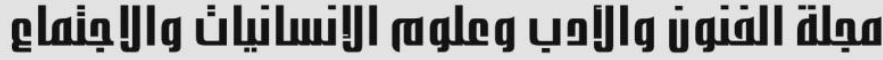

Journal of Arts, Literature, Humanities and Social Sciences www.jalhss.com

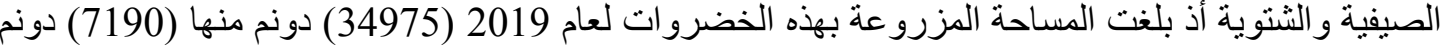

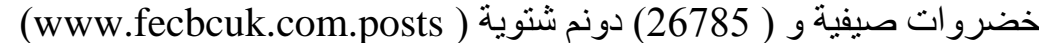

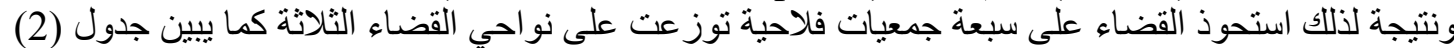

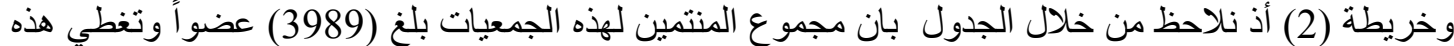

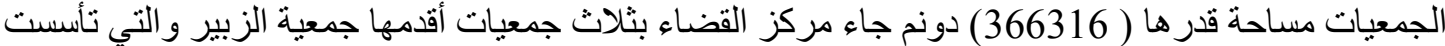

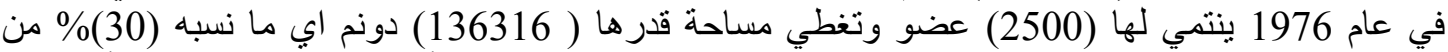

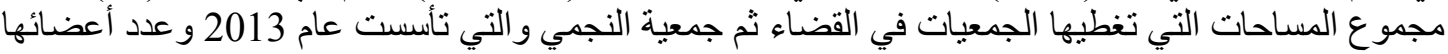

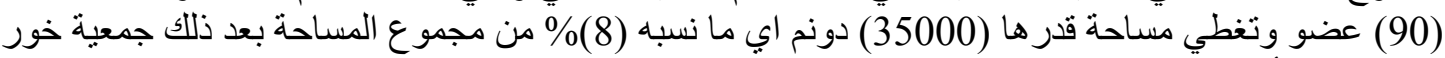

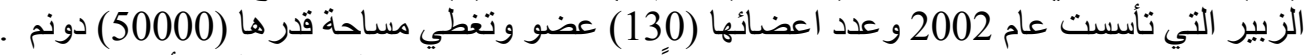

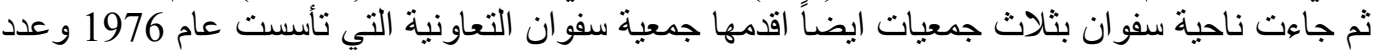

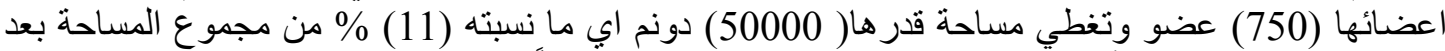

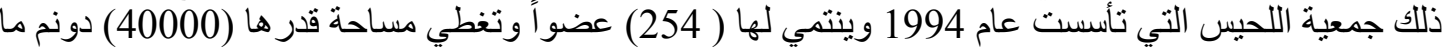

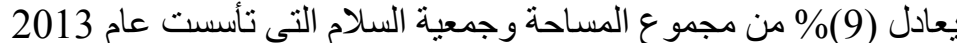

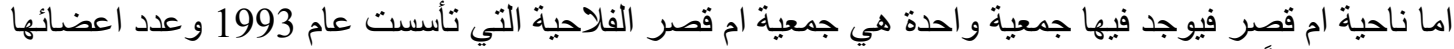
(180) عضواً وتغطي مساحة قدرها (31000) دونم اي ما يعادل (7)\% من مجموع المساحة التي تغطيها

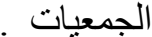

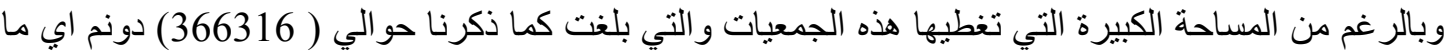

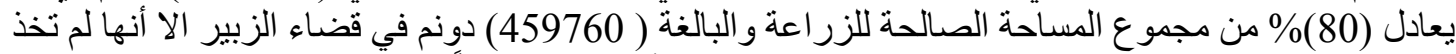

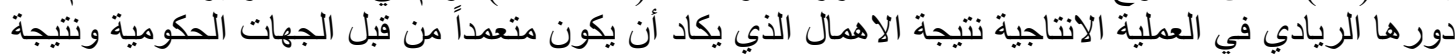
مجمو عة من المشاكل التي سنتطرق لها خلال البحث

جدول (2) (2) (2)

الجمعيات الفلاحية في قضاء الزبير لعام 2019

\begin{tabular}{|c|c|c|c|c|c|}
\hline تلنسباحة المئوية التي & المساحة التي تغطيها & عدد الاعضاء & سنة التأسيس & اسم الجمعية & الوحدة الادارية \\
\hline 30 & 136316 & 2500 & 1976 & الزبيز & \multirow{3}{*}{ مركز القضاء } \\
\hline 8 & 35000 & 90 & 2013 & النجمي & \\
\hline 11 & 50000 & 130 & 2002 & خور الزبير & \\
\hline 9 & 40000 & 254 & 1994 & اللحيس & \multirow{3}{*}{ سفوان } \\
\hline 11 & 50000 & 750 & 1976 & سفوان & \\
\hline 5,2 & 24000 & 85 & 2013 & السلام & \\
\hline 7 & 31000 & 180 & 1993 & ام قصر & ام قصر \\
\hline 80 & 366316 & 3989 & \multicolumn{3}{|c|}{ المجــــــــــوع } \\
\hline
\end{tabular}

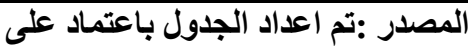

الاتحاد العام للجمعيات الفلاحية التعاونية في البصرة البحة سجلات رسمية، 2017 


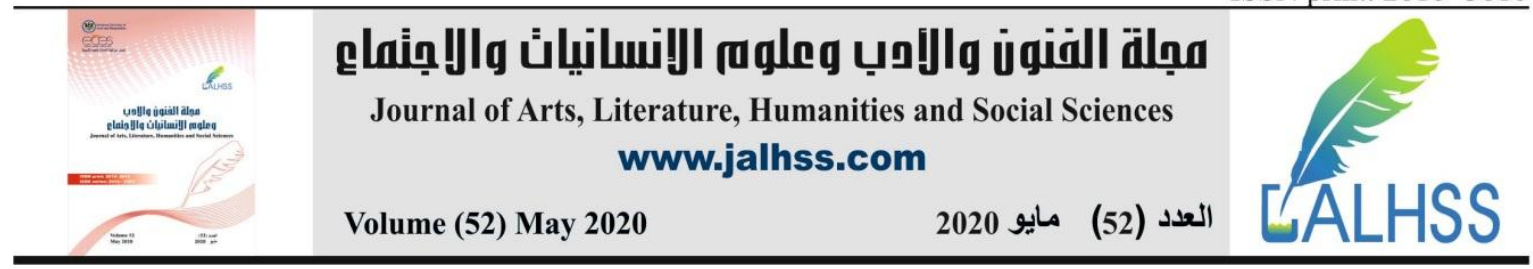

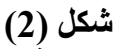

المساحات التي تغطيها الجمعيات التعاونية الفلاحية في قضاء الزبير لعام 2019

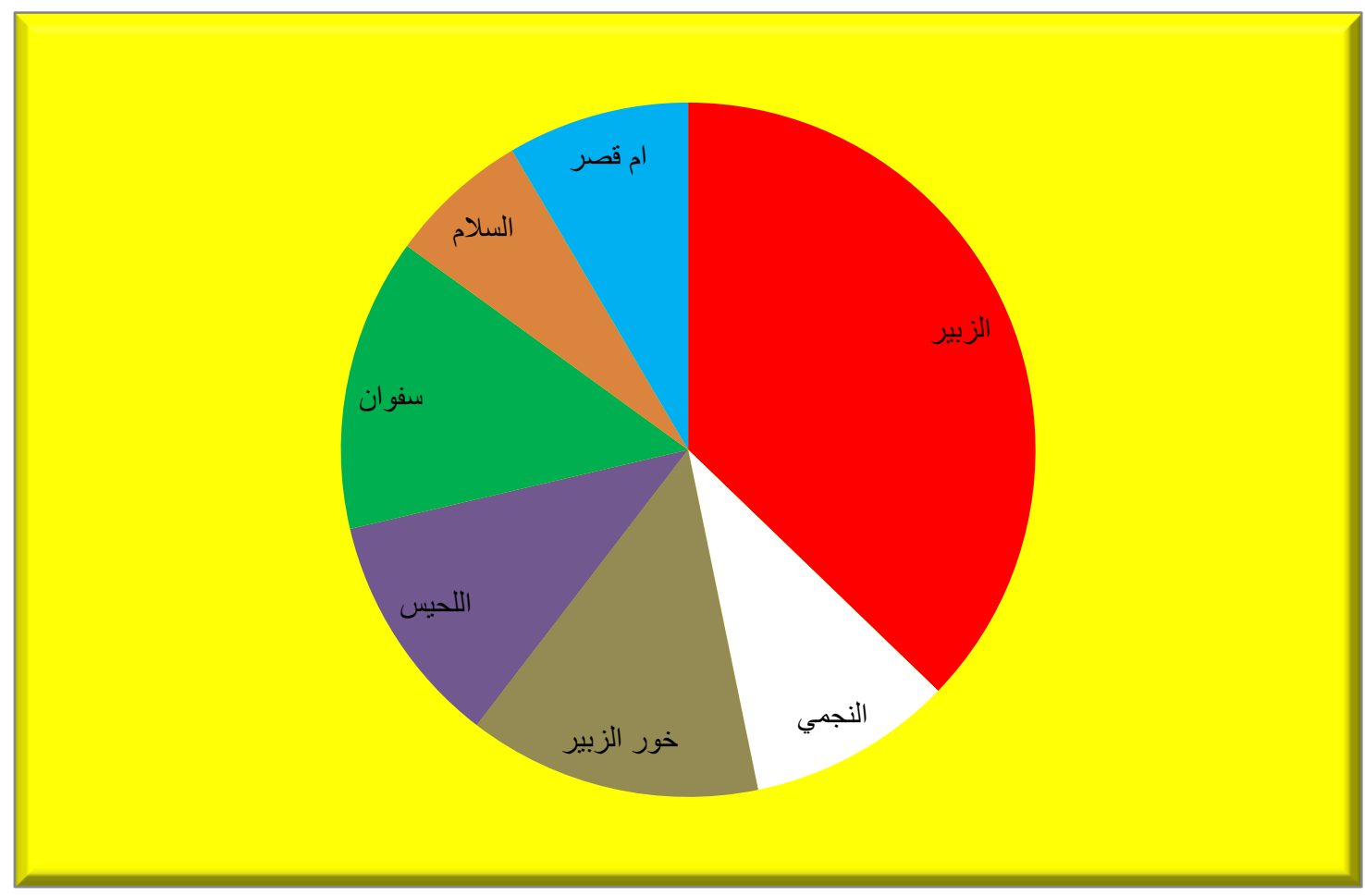

(2) - (المصدر جدول (2) - 2) 


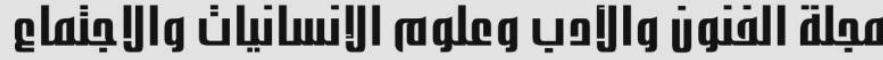

Journal of Arts, Literature, Humanities and Social Sciences www.jalhss.com

خريطة (2)

التوزيع الجغرافي للجمعيات التعاونية الفلاحية في قضاء الزبير

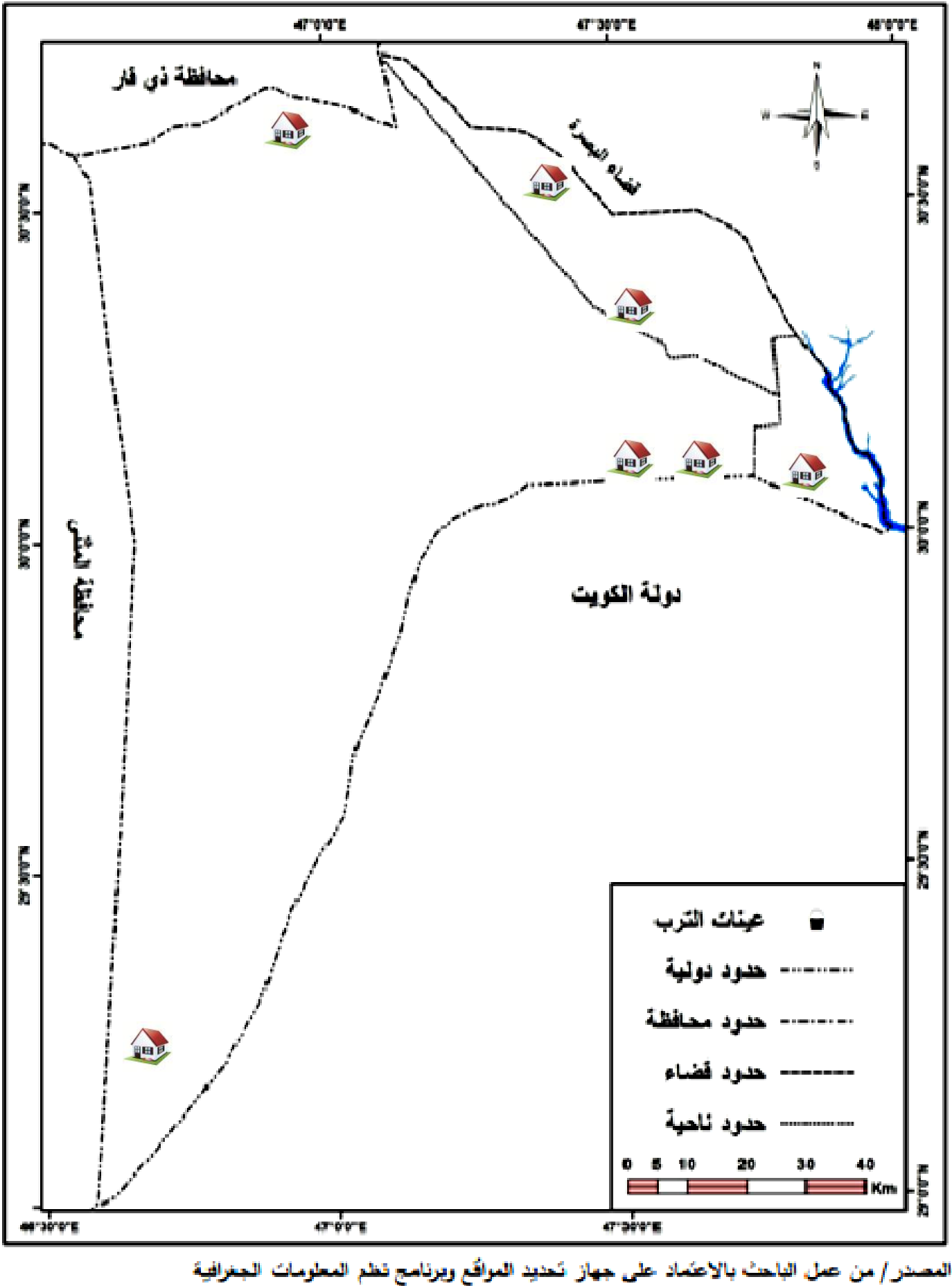




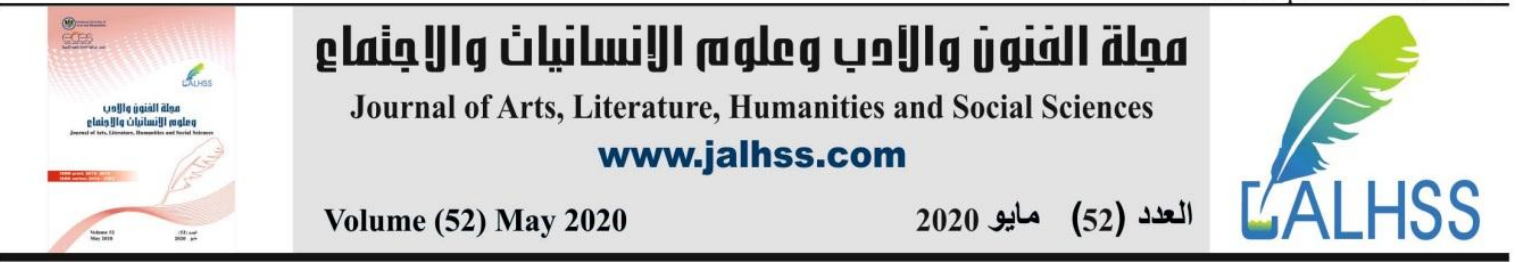

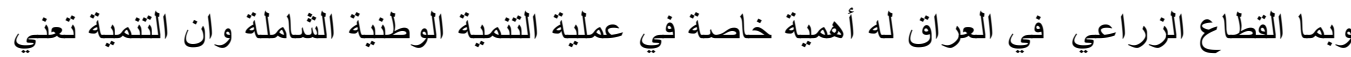

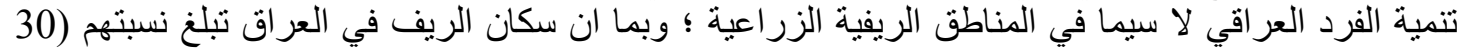

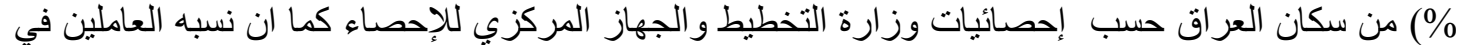

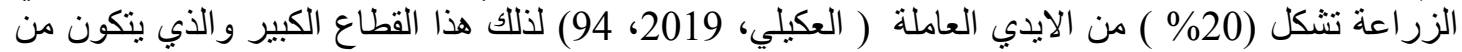

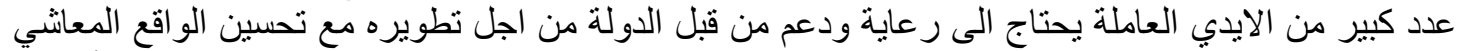

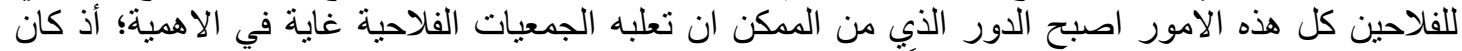

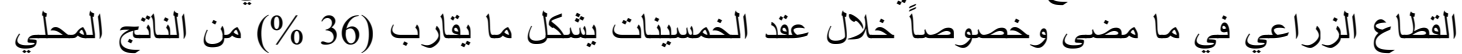

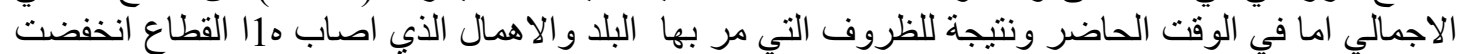

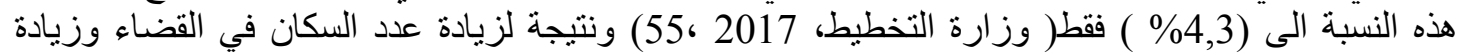

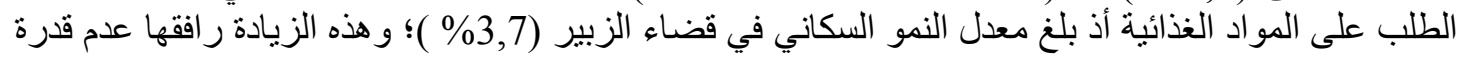

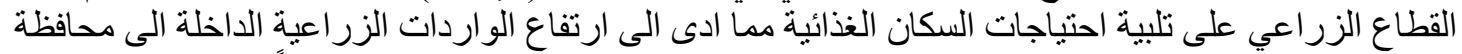

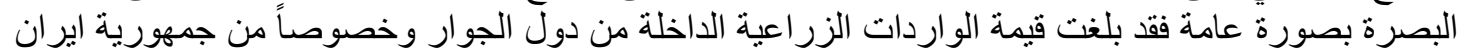

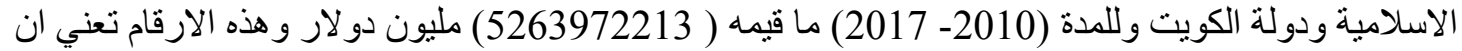

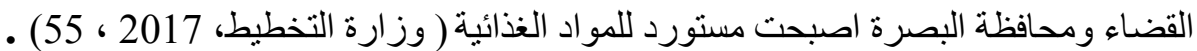

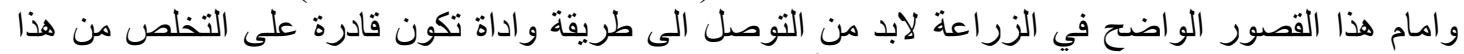

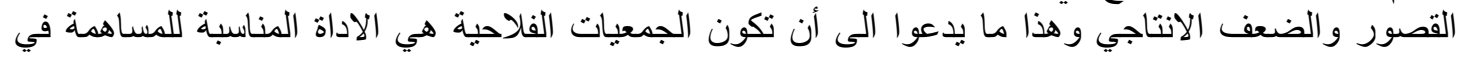

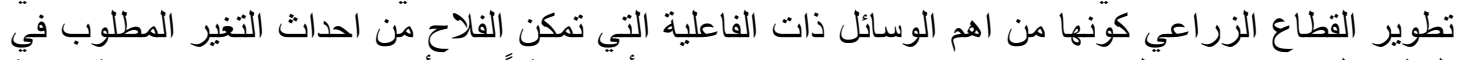

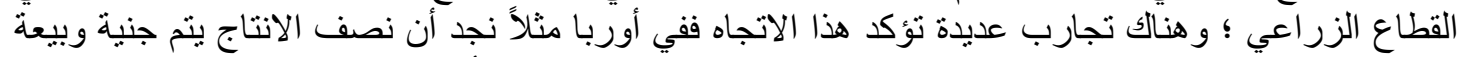

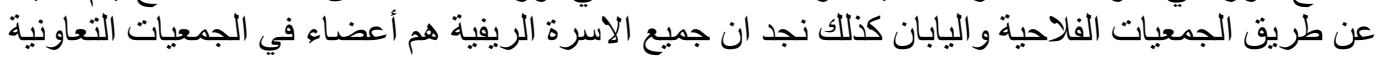

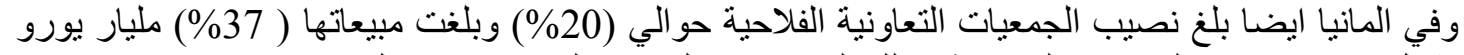

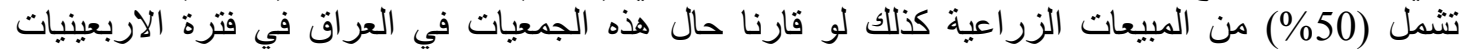

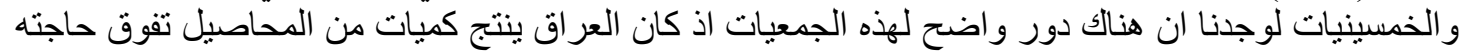

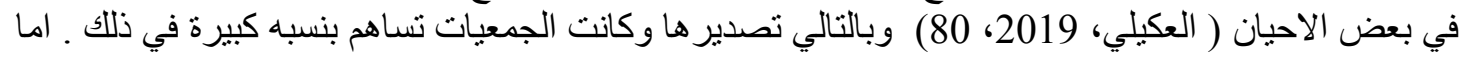

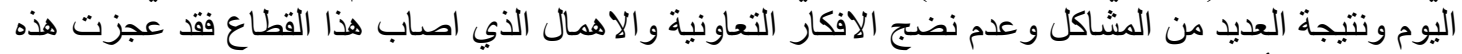

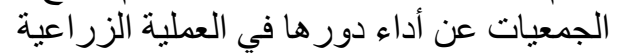

\section{مصادر تمويل الجمعيات التعاونية في قضاء الزبيز}

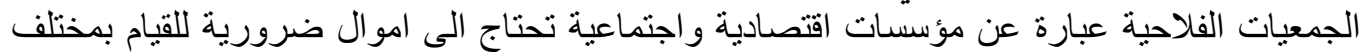

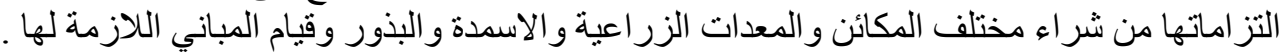

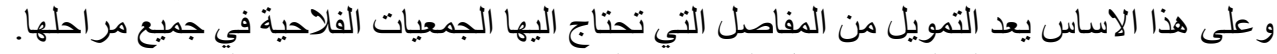

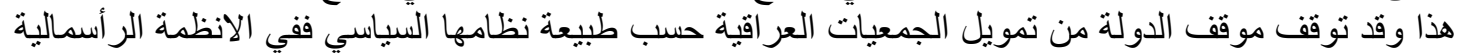

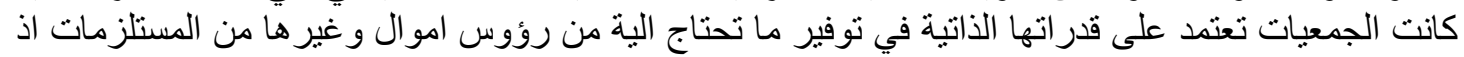

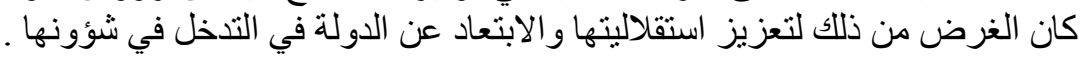

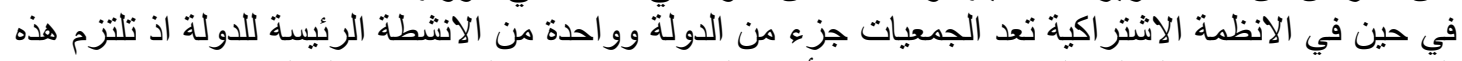

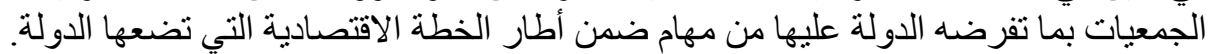

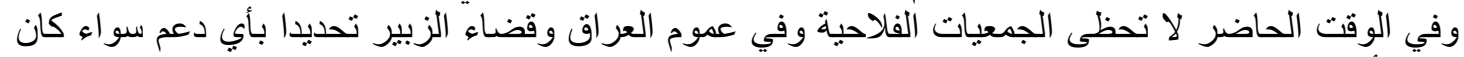

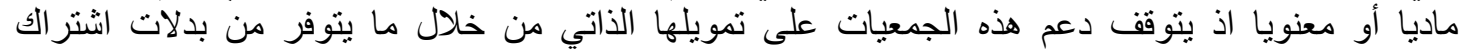

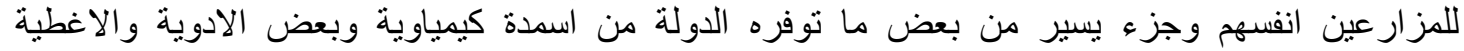

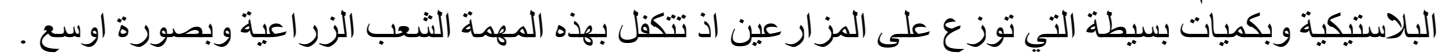

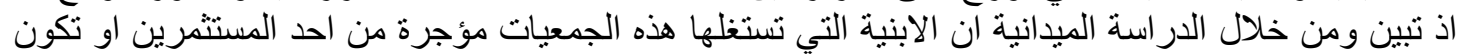

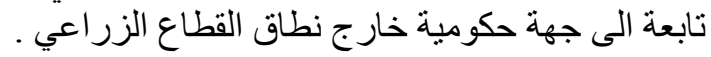




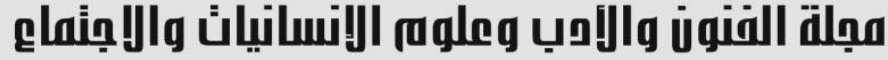

Journal of Arts, Literature, Humanities and Social Sciences www.jalhss.com

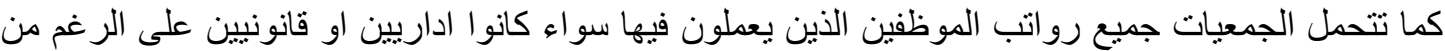

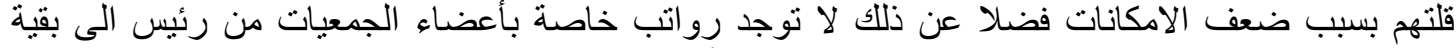

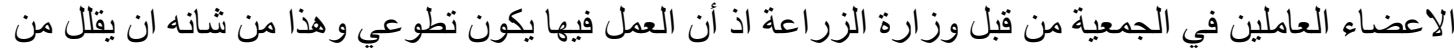

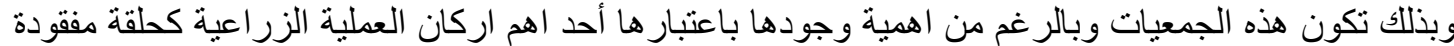

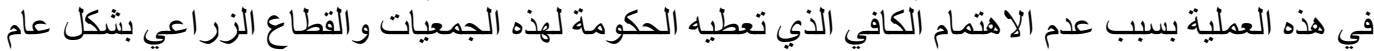

\section{المشكلات التي تواجه الجمعيات التعاونية في قضاء الزبيز التيزي}

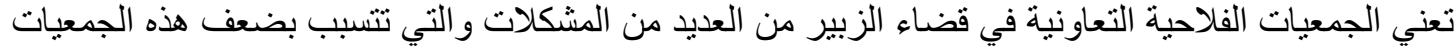

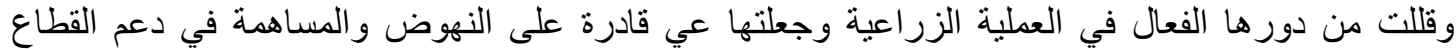
الزر اعي ومن هذه المشكلات

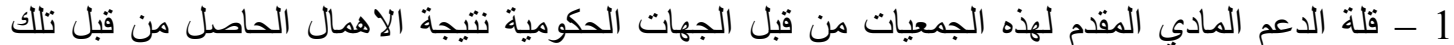

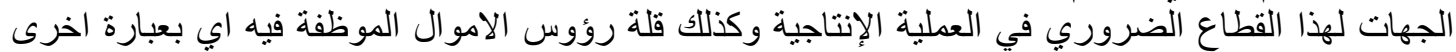

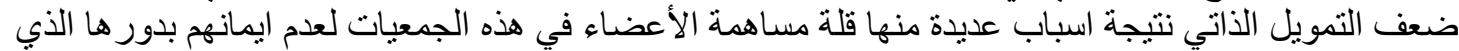

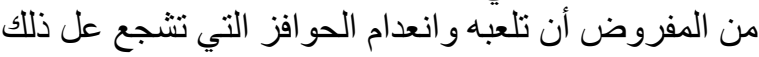

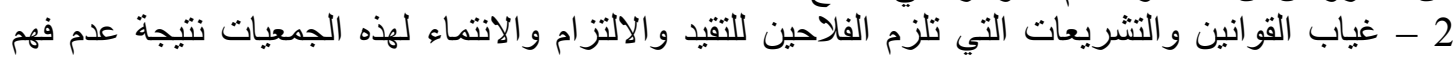

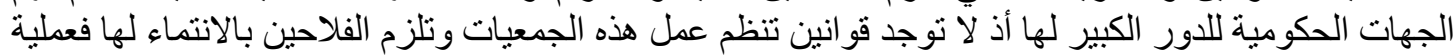

الانتماء عملية فردية لا أكثر

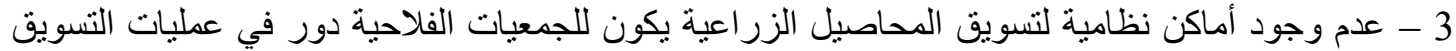

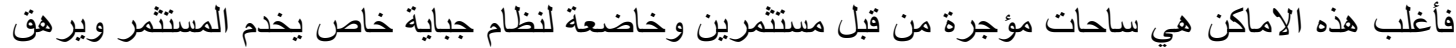

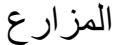

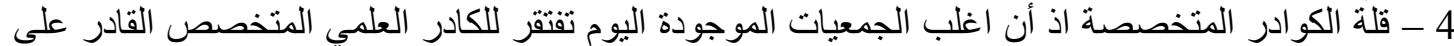

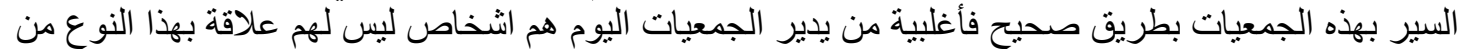

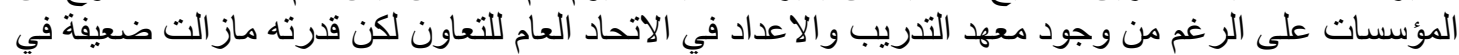

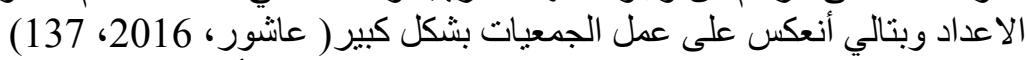

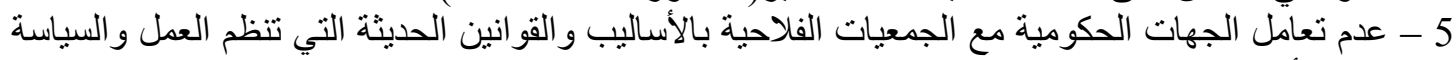

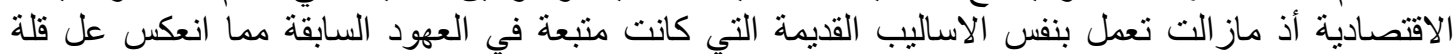
مساهمتها الفعالة في تحقيق التنمية

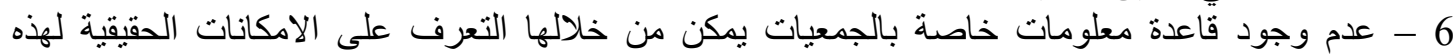

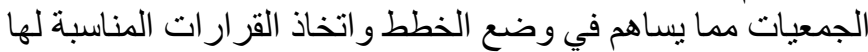

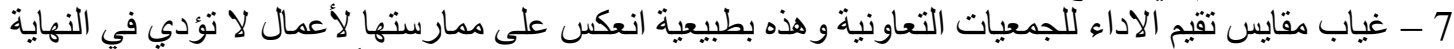

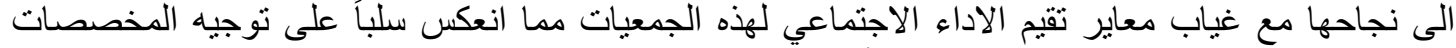

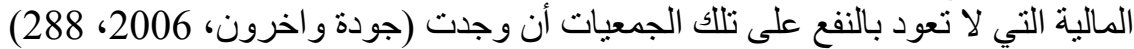

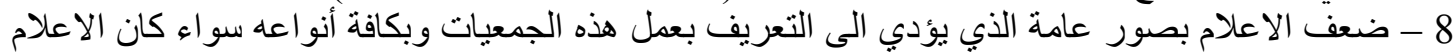

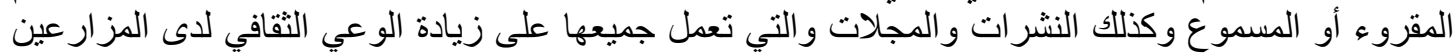

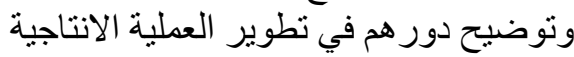

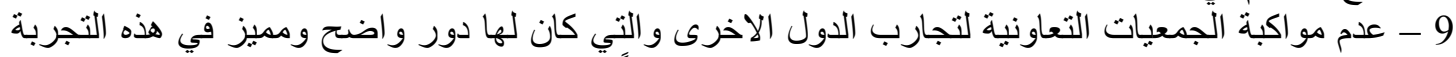

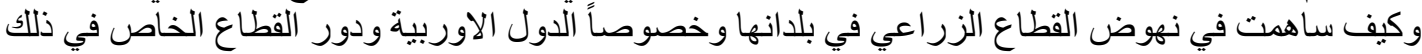




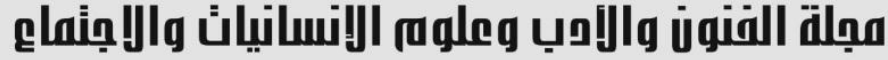

Journal of Arts, Literature, Humanities and Social Sciences www.jalhss.com

\section{الاسنتناجات والتوصيات}

1 - كانت البدابة الفعلية للجمعيات الفلاحية في العراق بصورة النواتيات عامة بعد صدور قانون الاصلاح الزراعي رقم (30) لسنة 1958 وقانون رقم (117) لسنة 1970 اذ نصت هذه القو انيين عل اقامة جمعيات تعاونية فلاحية

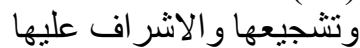
2 - كان الهدف من هذه الجمعيات هو زيادة مساهمتها في الناتج المحلي و الاجمالي وتحسين الانتاج وهذا الهدف لم يتحقق في الوقت الحاضر ألرف 3 - على الر غم من أهمية هذه الجمعيات الا انها لم تؤدي الدور المنشود من تأسيسها بسبب الكثير من المشكلات التي تعيق عملها 4 - بالرغم من كثرة الموارد سو اء كانت طبيعية او بشرية التي يتصف بها القطاع الزر اعي لا انه بعاني من

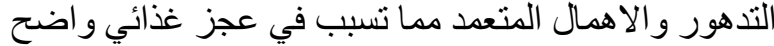
5 - تعاني الجمعيات الفلاحية في قطاع الزبير الكثير من المشكلات التي عالتي حالت دون تفعيل دور ها الحقيقي في

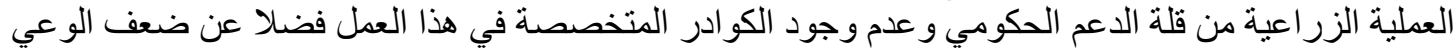

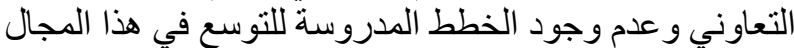
6 - نقص البحوث و الدر اسات الخاصة في هذا المجال بسبب نقص المعلومات و البيانات الخاصة بالجمعيات من

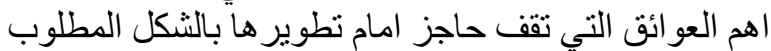

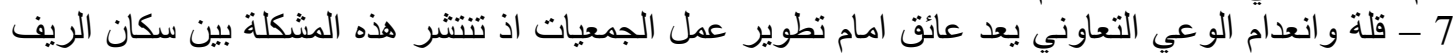

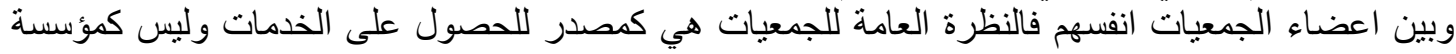

1 - تقديم الدعم المطلوب لهذه الجمعيات وبكافة اشكاله سو اء كان ماديا او معنويا واستقطاب جميع الفالحين الذين

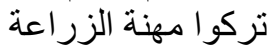

2 - تفعيل دور المصرف الزفر الزّرة اعي التعاوني ليسهل من عملية تمويل هذه الجمعيات اذ من الممكن ان يؤدي دورا

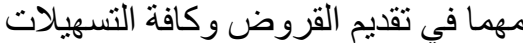
3 - العمل على توعية الاشخاص الذين يعملون على ادارة الجمعيات الفلاحية وتوفير الكوادر المتخصصة بهذا

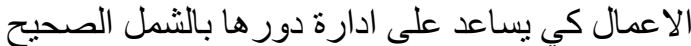

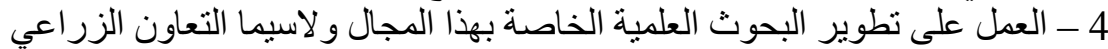

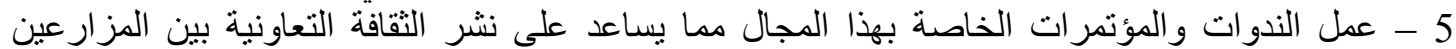
و العاملين فيها 6 - على وزارة الزراعة ان تأخذ دور ها في هذا المجال وكافة المؤسسات التابعة لها من خلال اجر اء حملات

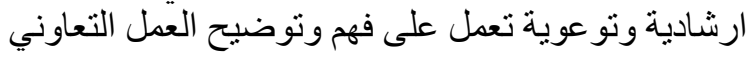




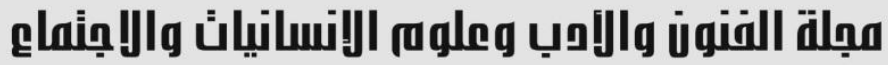

Journal of Arts, Literature, Humanities and Social Sciences

www.jalhss.com

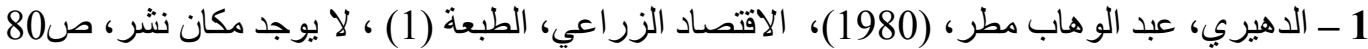
2 - العتيبي، محمد الفاتح عبد الوهاب، الجمعيات التعاونية و أسس قيام المشروع التشعة التعاوني، على الموقع،

WWW.grenc.com

3 - الجبوري، حاكم حمزة، (1989)، و اقع و افاق الحركة التعاونية الانتاجية في العراق، رسالة ماجستير ،معهد

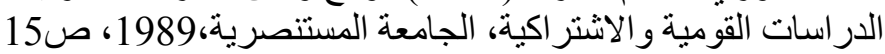

4 - المسالمة، عبد الحميد حامد، (1982)، الجهاز الاداري في الجية الجمعيات التعادية التعاونية الفلاحية ودورة في النشاط

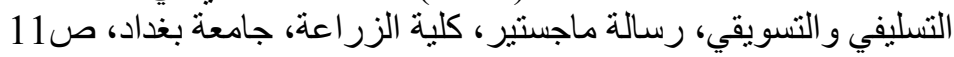

5 - الدهيري، عبد الوهاب، (1975)، اسس مبادئ الاقتصاد الزر اعي، الطبعة (2) ،مطبعة العاني، بغداد،

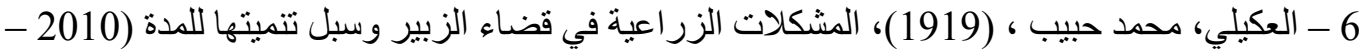

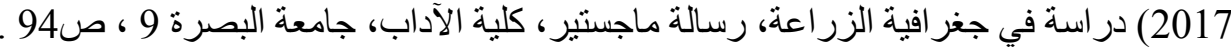

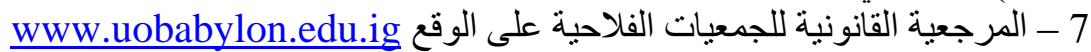

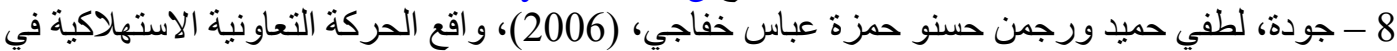

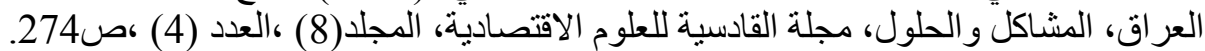

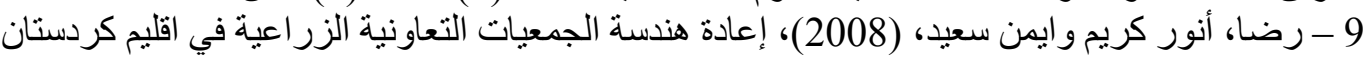

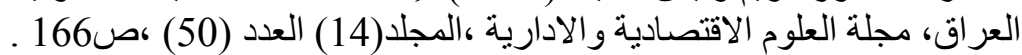

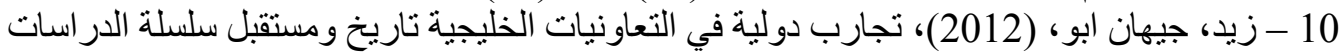

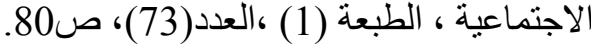

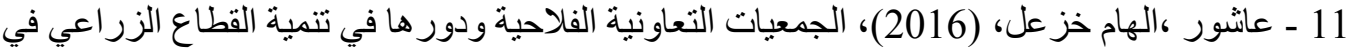

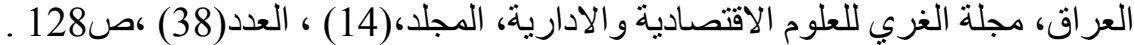

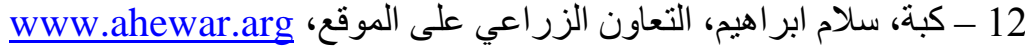

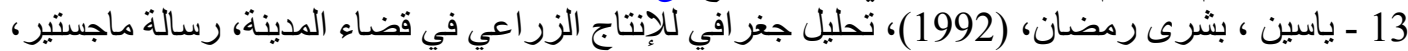

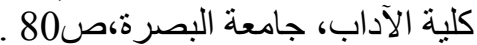

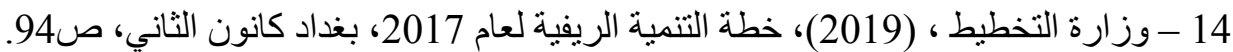

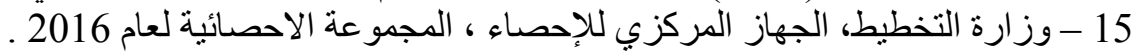

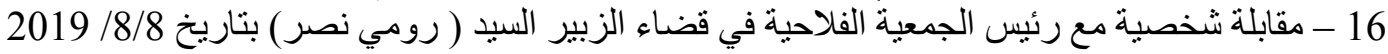
www.fecebcuk.com.posts -17 


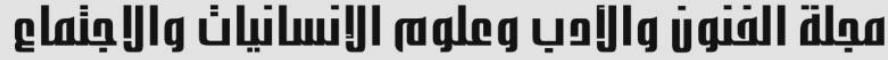 \\ Journal of Arts, Literature, Humanities and Social Sciences www.jalhss.com \\ Volume (52) May 2020 \\ العدد (52) مايو 2020}

\section{References}

1 - Al-Dahiri, Abdel-Wahab Matar, (1980), Agricultural Economics, Edition (1), There is no place to publish, p. 80

2 - Al-Otaibi, Mohamed Al-Fateh Abdel-Wahab, cooperative societies and the foundations of the establishment of the cooperative project, on the site, www.grenc.com

3 - Al-Jabouri, Hakim Hamza, (1989), The Reality and Prospects of the Productive Cooperative Movement in Iraq, Master Thesis, Institute of National and Socialist Studies, Al-Mustansiriya University, 1989, p. 15

4 - Al-Masalmeh, Abdul Hamid Hamid, (1982), the administrative body in the agricultural cooperative societies and a course in the marketing and credit activities, Master Thesis, College of Agriculture, University of Baghdad, p. 11

5 - Al-Duhairi, Abdel-Wahab, (1975), The foundations of the principles of agricultural economics, Edition (2), Al-Ani Press, Baghdad, p. 244.

6 - Al-Okaili, Muhammad Habib, (1919), Agricultural Problems in the Zubair District and Ways to Grow it for the Period (2010-2017), Study in the Geography of Agriculture, Master Thesis, College of Arts, University of Basra 9, p. 94.

7 - The legal reference for peasant associations on the website www.uobabylon.edu.ig 8 - Joudeh, Lutfi Hamid and Rajman Husnu Hamza Abbas Khafaji, (2006), The Reality of the Consumer Cooperative Movement in Iraq, Problems and Solutions, AlQadisiya Journal of Economic Sciences, Volume (8), No. (4), p. 274.

9 - Reda, Anwar Karim and Ayman Saeed, (2008), Re-engineering of Agricultural Cooperative Associations in the Kurdistan Region of Iraq, Journal of Economic and Administrative Sciences, Volume (14) No. (50), P.166.

10 - Zaid, Jihan Abu, (2012), International experiences in Gulf cooperatives, history and future of the series of social studies, Edition (1), No. (73), p. 80.

11 - Ashour, Elham Khazal, (2016), Agricultural Cooperative Societies and Their Role in the Development of the Agricultural Sector in Iraq, Al-Ghary Journal of Economic and Administrative Sciences, Volume, (14), No. (38), p. 128.

12 - Kibbeh, Salam Ibrahim, agricultural cooperation on the website, www.ahewar.arg

13 - Yassin, Bushra Ramadan, (1992), Geographical Analysis of Agricultural Production in Al-Madinah District, Master Thesis, College of Arts, University of Basra, p. 80.

14 - Ministry of Planning, (2019), Rural Development Plan 2017, Baghdad, January, p. 94.

15 - Ministry of Planning, Central Statistical Organization, Statistics Group 2016.

16 - Personal interview with the President of the Agricultural Society in the Zubair district, Mr. (Rumi Nasr) on 8/8/2019

17 - www.fecebcuk.com.posts 